\title{
Hands-On Method for Teaching Design of Mechanical Components Course
}

\section{Dr. Harold L. Stalford, University of Oklahoma}

Prof. Harold Stalford received M.S. (1966) and Ph.D.(1970) in Mechanical Engineering from the University of California, Berkeley, California and B.S.(1965) from Oklahoma State University. After being on the faculties at the Virginia Polytechnic Institute and State University and at the Georgia Institute of technology, he served as the Director of the School of Aerospace and Mechanical Engineering 1995-2000 Director and continues on as Professor since 1995. Dr. Stalford has spent two sabbaticals (2001-2002 and 2008-2009) with the Sandia National Laboratories, Albuquerque, NM and has served as consultant to Sandia's Microsystems Science, Technology \& Components Division since 2001. His major research interest in the oil and gas industry is telemetry of borehole sensor data to the surface during drilling, completions, and production. Dr. Stalford's broad area of research is in microsystems and nanotechnology, seeking new and novel solutions to challenging oil and gas problems. His work with Sandia has focusing on designing, fabricating, testing and characterizing various micro/nanotechnology systems that includes Microelectromechanical systems (MEMS), tunable MEMS devices, RF nanotechnology, microfluidics, on-chip low power micro-sensors and electronics, micro-resonators, micro-sensors, and quantum systems. Dr. Stalford has extensive research experience in automated/intelligent control systems and telemetry for autonomous vehicles. 


\title{
Hands-On Method for Teaching Design of Mechanical Components Course
}

Harold L. Stalford. School of Aerospace and Mechanical Engineering; University of Oklahoma, Norman, OK 73019; email: stalford@ ou.edu Phone: (405) 325-1742

\begin{abstract}
Described in this paper are the salient features of teaching a junior level Design of Mechanical Components course using a hands-on method, taught three times in the past three years with high reviews from students and engineers. Rubrics and grading criteria are presented. The course covers the analysis and design of mechanical components such as fasteners, springs, bearings, gears, shafts, clutches, brakes, etc. Prerequisites include a course on solid mechanics or mechanics of materials. Students coming into the course are expected to be fluent in performing free-body-diagrams, static equilibrium analysis, stress-strain analysis, Mohr's circle analysis, deflection analysis, etc. on structures with various loads (e.g., point forces, moments, distributive loading) in axial, torsional, and bending configurations.

On the first day of class, the students form teams of 5 to 6 students per team. Each team picks its choice of a vehicle, machine or system from which they will pick all mechanical components for analysis and design in the course. Each team is required to carry out four mechanical component projects and write project reports and make presentations. Each project covers a time period of three to four weeks. For example, fasteners and springs projects are projects that require three weeks; bearings and gears projects require four weeks. Each team makes a presentation on each of the four projects during the semester. The presentations are judged by engineers from industry.

The reports and presentations are required to cover analysis and design of team's selected mechanical component from team's same selected vehicle. The reports and presentations are required to cover component manufacturability and cost, environmental conditions, dimensions, loading conditions, design and statics treatment, stress-strain analysis, fatigue analysis, and simulation. On each project, a team is required to select a team leader and to divide up the workload among all team members.

The hands-on method is designed so that (a) the instructor can mentor and coach students' "thinking and doing" in a multidimensional process of learning, (b) peer-to-peer learning is greatly enhanced, (c) students are encouraged to defend their way of thinking resulting in a meeting of the minds between instructor and student, and (d) self-regulated learning is promoted and encouraged.
\end{abstract}




\title{
Hands-On Method for Teaching Design of Mechanical Components Course
}

\author{
Harold L. Stalford. School of Aerospace and Mechanical Engineering; University \\ of Oklahoma, Norman, OK 73019; email: stalford@ ou.edu Phone: (405) 325- \\ 1742
}

\section{Introduction}

Richard Feynman ${ }^{1}$, in describing one of his very interesting experiences while teaching in Brazil, made the observation "After a lot of investigation, I finally figured out that the students had memorized everything, but they didn't know what anything meant". This same observation is not too far from being true in undergraduate education in the United States wherein students are memorizing their way through most of the curriculum. In an US News and World Report $\operatorname{article}^{2}$, "High School Students Need to Think, Not Memorize", an Advanced Placement biology teacher is quoted "Students go through the motions of their lab assignments without grasping why, and 'the exam is largely a vocabulary test'".

David Perkins ${ }^{3}$, co-director of Harvard Project Zero, a research center for cognitive development, and senior research associate at the Harvard Graduate School of Education, points out several observations in his article on "Teaching for Understanding". (1) "The student might simply be parroting the test and following memorized routines for stock problems."; (2) "People can acquire knowledge and routine skills without understanding their basis or when to use them."; (3) "A student might be able to regurgitate reams of facts and demonstrate routine skills with very little understanding."; and (4) "Schools are providing the wrong apple. The apple of knowledge is not the apple that truly nourishes. What we need is the apple of understanding (which of course includes the requisite knowledge)." Perkins offers six priorities for "teaching for understanding" and suggests that these will mobilized a powerful armamentum for building students' understanding.

1. Make learning a long-term, thinking-centered process. Teaching is less about what the teacher does than about what the teacher gets the students to do. A long term, thinking-centered process seems central to building students' understanding.

2. Provide for rich ongoing assessment. While there are many reasonable approaches to ongoing assessment, the constant factor is the frequent focus on criteria, feedback, and reflection throughout the learning process.

3. Support learning with powerful representations. The teacher teaching for understanding needs to add more imagistic, intuitive, and evocative representations to support students' understanding performances.

4. Pay heed to developmental factors. Teachers teaching for understanding do well to bear in mind factors like complexity, but without rigid conceptions of what students can and cannot learn at certain ages. 
5. Induct students into the discipline. Accordingly, the teacher teaching for understanding needs to undertake an extended mission of explicitly raising consciousness/awareness about the structure and logic of the disciplines taught.

6. Teach for transfer far and wide. Teachers teaching for a full and rich understanding need to include understanding performances that reach well beyond the obvious and conventional boundaries of the topic.

$\mathrm{Kolb}^{4}$ develops the concept of "experiential learning" with experience being the source of learning in four basic elements of the learning cycles (i.e., concrete experience, reflective observation, abstract conceptualization, and active experimentation). In the development of approaches that work for "teaching for experiential learning", Wurdinger and Carlson ${ }^{5}$ indicate that their five approaches are guided by the following six principles: (1) promoting hands-on learning, (2) using a problem solving process, (3) addressing real world problems, (4) encouraging student interaction with each other and the content, (5) engaging in direct experience, and (6) using multiple subjects to enhance interdisciplinary learning. Studentcentered learning is incorporated into their five approaches wherein it encourages individuals to become self-directed learners. They point out that when students interact with one another and learn how to solve real world problems that have significance to them, they become excited about coming to school every day.

In this paper, we address teaching a third year core course in the mechanical engineering curriculum of the School of Aerospace and Mechanical Engineering at the University of Oklahoma called "Design of Mechanical Components" in which fatigue, failure, and life expectancy of mechanical components are the key concepts to be understood as outcome. A hands-on method is presented for building students' understanding of these key concepts. It encompasses, to a large degree, Perkins' six priorities, Kolb's four basic elements of the learning cycles, and the six guiding principles of Wurdinger and Carlson. In the next section, we present pedagogy and course structure layout for the hands-on method.

\section{Pedagogy and Course Structure}

Design of Mechanical Components is a junior level core course in the mechanical engineering curriculum. Understanding fatigue, failure, and life expectancy as it relates to the design of mechanical components is the ultimate objective of the course. In teaching the course, we normally use the textbook "Fundamentals of Machine Component Design" by Juvinall and Marshek ${ }^{6}$; it covers the design of various mechanical components (i.e., fasteners, springs, bearings, gears, etc.) from Chapter 10 through Chapter 17 as well as the basic theory of failure and fatigue concepts in Chapters 6-8. The material of Chapters 1-5 has already been covered in a solid mechanics ${ }^{7}$ prerequisite course. On the first day of the course, the class forms teams of 6 students per team; students make their own team selection. The course is structured in such a way that the maximum number of teams is 8 which in turn limits the class size to 48 students. If 4 students per team are used, then the class size is limited to 32 students. The course meets 
Tuesdays and Thursdays for 1 hour and 15 minutes per class. The course is structured with 4 projects associated with 4 mechanical components-Project1 (Fasteners), Project2 (Springs), Project3 (Bearings) and Project4 (Gears). Projects 1 and 2 are projects of 3 weeks each. Projects 3 and 4 are projects of 4 weeks each. For each project, each team performs fatigue analysis on their mechanical component, writes a report and makes a presentation.

On the first day of the class, each team picks a vehicle or system that contains all 4 mechanical components. The format of the course with the hands-on method was taught in the spring semesters of 2012 and 2013. During the 2012 and 2013 semesters, the teams picked the vehicles listed in Table 1.

Table 1 Vehicles selected by teams during the 2012 and 2013 semesters Boeing 787 Dreamliner, 1969 Pontiac Firebird, 1971 Camaro drag car, 1990 BMW 325i E30, 1995 Ford F-150, 1996 Ford Mustang Cobra, 2005 Dodge Ram 1500, 2006 Ford F150, 2010 Chevrolet Camaro, 2012 Ford F-150, Traxxas Monster Mutt RC car, BMW R1200GS motor cycle, Schwinn City Series bicycle. 2011 Sooner Racing Team car, 2012 Sooner Off Road vehicle, 2013 Sooner Off Road vehicle

Furthermore, on the first day of the class, each team picks a fastener from its vehicle for Project 1. During the 2012 and 2013 semesters, the teams picked the fasteners listed in Table 2.

Table 2 Fasteners selected by teams during the 2012 and 2013 semesters Eddie Bolt ${ }^{\circledR}$, engine head bolt/stud, wheel stud, front brake caliper mounting bolt, bolt fastens gas pedal to welded joint, wheel nut, bumper bolt, rear brake caliper mounting bolt, chain sprocket mounting bolt, motor cycle kickstand mounting bolt, bicycle kickstand mounting bolt

At the end of Project 1, each team selects a spring from its vehicle. During the 2012 and 2013 semesters, the teams picked the springs listed in Table 3 for Project 2.

Table 3 Mechanical springs selected by teams during the 2012 and 2013 semesters Aircraft landing gear spring, Eibach front suspension coil spring, front suspension spring, rear suspension coil spring, CVT clutch secondary spring, front door hinge compression spring, right intake valve spring, seat belt latch spring, bicycle seat support spring

At the end of Project 2, each team picks a bearing from its vehicle. During the 2012 and 2013 semesters, the teams picked the bearings listed in Table 4 for Project 3.

Table 4 Bearings selected by teams during the 2012 and 2013 semesters

Front main shaft bearing of the Trent 1000 Rolls Royce engine, hub bearing, front wheel ball bearing, rear wheel inner ball bearing, differential bearing, eccentric housing bearing, alternator drive-end bearing, rear differential assembly, idler pulley ball bearing, clutch pilot bearing, eccentric pillow block bushing bearing, motor cycle front wheel ball bearing, bicycle rear wheel bearing

At the end of Project 3, each team picks a gear from its vehicle. During the 2012 and 2013 semesters, the teams picked the gears listed in Table 5 for Project 4. 
Table 5 Gears selected by teams during the 2012 and 2013 semesters

Fan drive gear system for Pratt and Whitney PW1000G engine, spiral bevel gear, speedometer gear, window regulating spur gear, window regulator motor gear, drive sprocket and flange assembly, drive chain sprocket assembly, slipper clutch gear, starter motor planetary gear system, starter motor pinion gear, Mini Baja sprocket chain drive, camshaft sprocket, Whipple supercharger helical gear, motor cycle crankshaft sprocket, bicycle rear wheel 14 tooth sprocket

We briefly describe the tasks that each team performs on a project. Below, we give more details about the projects. At the start of each project and after the selection of its mechanical component, each team organizes for the workload of the project. The internet and library resources are utilized as needed to obtain information and data about the team's vehicle and mechanical component. The manufacturing method of the mechanical component is described and the material is determined. As much as possible, students make their own measurements on mechanical component. A design of the mechanical component is provided. The dimensions, material properties, yield limits and ultimate strengths are obtained. Vehicle operational loading conditions that create loads on the mechanical component are determined. Solid mechanics analysis is conducted (e.g., loads, free-body diagrams, statics, stress, strain, Mohr circle analysis, etc.). Fatigue analysis is performed and life expectancy is determined. Bonuses are given to team members that conduct simulation analysis on the mechanical component. The team writes up a project report. The team presents project findings using PowerPoint slides. Project results in the report and in the presentation are supported by calculations documented in an Excel file. The results of each project are submitted in e-form on a thumb drive or online according to syllabus schedule and include e-copies of report (WORD document), presentation (PowerPoint slides) and calculations (Excel file). All reference material used outside own work is listed.

Team structure involving 6 team positions is recommended-Project Leader, Project Chief of Staff, and Integrators 1-4. All team positions rotate as fairly as possible throughout all four projects. Project Leader keeps project on track. Project Chief of Staff keeps Integrators 1-4 on track. Integrator 1 integrates "report" inputs from all team members. Integrator 2 integrates "presentation" inputs from all team members. Integrator 3 integrates TEAM Excel page (calculations and plots) and all six individual Excel pages (calculations and plots) into single Excel file. Integrator 4 integrates all six individual fatigue plot results into one single plot and provides it for the TEAM Excel file page.

Class time is structured so that team members can interact among themselves as well as interact with the instructor and the rest of the class. Teams use class time to bounce their ideas and approaches off other class members as well as the instructor.

Grading: Each of the 4 projects is worth $20 \%$ of grade. The project grades account for $80 \%$ of course grade. The Final Exam and/or Instructor's Qualitative Grade are worth $20 \%$ of the course grade. Each project (worth $20 \%$ and 20 points) has three subgrade aspects-report grade is $60 \%$ (12 points), presentation is $20 \%$ ( 4 points), and progress is $20 \%$ ( 4 points). Team progress on 
project is graded during each class period according to milestones established in the class syllabus.

\section{Project Report Requirements-TEAM (50\%) and INDIVIDUAL (50\%)}

Tasks 1.1-1.7 and 3.1-3.3 described below are TEAM report tasks to be done by teamwork. Tasks 2.1-2.7 are INDIVIDUAL report tasks to be done by individual team members. The TEAM tasks are worth 50\% of report grade. The INDIVIDUAL tasks are worth 50\% of report grade.

Material for Project 1 Fasteners is provided in Chapter 10 in textbook ${ }^{6}$. Additional material recommended for reading can be found in the following papers: Burguete $\operatorname{paper}^{8}$ entitled "The effect of mean stress on the fatigue limit of high tensile bolts"; Patterson's paper" entitled "A Comparative Study of Methods for Estimating Bolt Fatigue Limits"; Peterson's Stress Concentration Factors ${ }^{10}$; and Gough's work "combine stresses" entitled "Some Experiments on the Resistance of Metals to Fatigue under Combined Stresses " ${ }^{11 "}$. Material for Project 2 Springs is provided in Chapter 12 in textbook ${ }^{6}$. Additional material recommended for reading can be found in Wahl ${ }^{12}$, Spotts ${ }^{13}$, and various spring design manuals ${ }^{14,15}$. Material for Project 3 Bearings is provided in Chapter 14 in textbook ${ }^{6}$. Additional material recommended for reading can be found in Harris ${ }^{16}$, Palmgren ${ }^{17}$, and various other papers ${ }^{18-21}$ that present real fatigue test data results for rolling contact. Additional material recommended for reading on the statistical treatment of fatigue experiments can be found in Johnson ${ }^{22}$ and Murthy ${ }^{23}$. Catalogues from industry (e.g., $\mathrm{NTN}^{24}$ ) are helpful in determining of fatigue life of bearings under a range of loading conditions. Harris ${ }^{16}$ provides many examples worked out in detail, including Ch16 (bearing structural materials), Ch18 (fatigue life), Ch19 (bearing endurance testing methods), Ch20 (Statistical methods to analyze endurance), and $\mathrm{Ch} 27$ (investigation and analysis of bearing failures). Chapters 15-17 in textbook ${ }^{6}$ provide material for Project 4 Gears. In particular, the Sample Problems 15.1D, 15.2, 15.3, 15.4, 15.5D given in Ch15 are helpful in carrying out tradeoff analysis between fatigue due to "tooth bending" and that due to "Hertzian contact stresses on a tooth". The fatigue analysis carried out in the Project 3 Bearings involving Hertzian contact stresses on a bearing has application in Project 4 Gears. The fatigue analysis methods utilized in Project 1 Fasteners has application to the "tooth bending" aspect of fatigue in Project 4 Gears. Additional material on "photoelastic study of stresses in gears" can be found in Dolan and Broghamer ${ }^{25}$. In carrying out fatigue analysis for roller chains and sprockets, consider additional references ${ }^{26-31}$.

\section{Rubrics for Grading Team Project Report}

The rubrics for grading the project report of a team are given in Table 6. The grading encompasses both quantitative and qualitative aspects of the report. The grading includes instructor's comments along with the quantitative score. The TEAM score is worth $50 \%$ and the 
INDIVIDUAL score is worth 50\%. Individual team members can earn an additional $5 \%$ by performing good quality stress analysis using simulation.

Table 6 Rubrics for Grading Team Project Report

\begin{tabular}{|c|c|c|c|}
\hline \multicolumn{2}{|r|}{ TEAM (50\%) Rubrics for Grading Team Project Report } & \multirow[b]{2}{*}{ Max } & \multirow[b]{2}{*}{ Score } \\
\hline & Description & & \\
\hline I & 1.0 Report Basics & 5 & \\
\hline II & 1.1 Project Definition, Goals, Vehicle, and Component & 5 & \\
\hline III & 1.2 Utility, Technology, Safety Issues, Manufacturing and Economics & 5 & \\
\hline IV & 1.3 Dimensions, Materials, and Environmental Conditions & 5 & \\
\hline $\mathrm{V}$ & 1.4 General Loading Conditions & 10 & \\
\hline VI & 1.5 Fatigue Tests & 5 & \\
\hline VII & 1.6 Fatigue Models & 5 & \\
\hline VIIII & 1.7 List of References & 5 & \\
\hline \multirow[t]{4}{*}{ IX } & 3.1 TEAM Summary and Conclusions & 5 & \\
\hline & TEAM Totals & 50 & \\
\hline & INDIVIDUAL $(\mathbf{5 0} \%)$ Rubrics for Grading Team Project Report & & \\
\hline & Description & $\operatorname{Max}$ & Score \\
\hline I & 2.0 Report Basics & 5 & \\
\hline III & 2.1 Design and Statics & 5 & \\
\hline IIII & 2.2 Stress-Strain Analysis & 10 & \\
\hline IV & 2.3 Fatigue Failure Analysis and Life Expectancy & 10 & \\
\hline V & 2.5 Calculations Documented in Excel File & 10 & \\
\hline VI & 2.6 INDIVIDUAL Summary and Conclusions & 5 & \\
\hline \multirow[t]{4}{*}{ VII } & 2.7 List of References & 5 & \\
\hline & INDIVIDUAL Totals & 50 & \\
\hline & INDIVIDUAL 2.4 Simulation Work (Bonus Max 5\%) & 5 & \\
\hline & TEAM, INDIVIDUAL, Bonus Totals & 105 & \\
\hline
\end{tabular}

\section{Project Report Tasks-TEAM (50\%)}

Task 1.0 Report Basics (TEAM): Report format is followed. Section titles have consistent format and match Task numbers. The report is professionally written; it is not written like a collection of website topics. Report is integrated and written as written by one person. Final points of results are clear. Title Page is to provide date, project (Mechanical Component Category), vehicle picked, mechanical component selected, Team\#, list of team members, and provide the names of team members of the six team positions- Project Leader, Project Chief of Staff, Integrators1-4. Format for report includes the following requirements.

- Typewritten: 12 point font, 1 inch margins all around, single space, and page numbers; 8.5"x11" paper, consistent format, paragraphs tabbed.

- Good English grammar; pictures/figures should be legible and numbered; pages and references are number. Figures/table captions have consistent format and numbered (figure captions below, table captions above). In part description, picture where/how it is used.

- All equations used in calculations must be in report, numbered in report, and presented in Excel file. References are numbered and listed using valid format, all work used referenced. In FBDs present loads shown w/correct units, key equations derived from FBDs.

Task 1.1 Project Definition, Goals, Vehicle, and Component (TEAM): What is the project? Describe the project in general terms so that a reader of the report gains understanding of what the project is about. What are the project goals? What is the team trying to accomplish in this 
project? Present a picture of the vehicle and indicate where the mechanical component is located. Provide a drawing or picture of the mechanical component. Describe the unique aspects of the particular mechanical component.

Task 1.2 Utility, Technology, Safety Issues, Manufacturing and Economics (TEAM): Describe the utility or function of the mechanical component and its technology. Describe any safety issues associated with the functioning of the mechanical component during vehicle operations. Identify at least three companies that manufacture the mechanical component. Describe what manufacturing methods are used to make the mechanical component. Perform mechanical component cost analysis (i.e., what does it cost to buy it?).

Task 1.3 Dimensions, Materials, and Environmental Conditions (TEAM): Provide complete geometry, dimensions, parameters, and material properties of the mechanical component together with the values. Describe any standards associated with the identity of mechanical component. Include values of $S_{u}$ (ultimate tensile strength), $S_{u s}$ (ultimate shear strength), $S_{y}$ (tensile yield strength) as well as Young's modulus $E$, shear modulus $G$, Poisson's ratio, etc. Indicate the temperature and corrosive environment that the mechanical component operates in during its lifetime on the selected vehicle. Indicate the operating temperature range of the mechanical component. For the Project 3 Bearings project, geometry, dimensions, diametral clearance and materials are addressed in Ch14 in textbook ${ }^{6}$ and Ch1 and Ch2 in Harris ${ }^{16}$. Examples are provided in Harris ${ }^{16}$ (e.g., Chapters $2-10,14,15,18,20$ ) that treats every type of bearing. Curvatures, curvature sum, curvature difference, elliptical contact area parameters ( $\mathrm{a}^{*}$, $b^{*}$ ), and line contact parameters are treated in Ch6 examples. For the Project 4 Gears, provide dimensions, data and equations needed for Hertz contact and tooth bending stresses calculations.

Task 1.4 General Vehicle Loading Conditions and Mechanical Component Loads (TEAM): Determine loading conditions acting on the mechanical component during its lifetime operations. The TEAM selects six (6) different/distinct max loading conditions, one for each team member. Provide free body diagrams (FBDs), complete with forces, moments, torques (bending, axial, torsion). Show statics equilibrium equations. For the Project 3 Bearings project, Ch14 in textbook ${ }^{6}$ presents the "bearing rating" method for conducting fatigue analysis. The "bearing rating" method is covered in greater depth in Harris' book in Ch18 (Fatigue life: LundbergPalmgren theory and rating standards), Ch21 (Permanent Deformation and bearing static capacity) and $\mathrm{Ch} 23$ (Application load and life factors). Equivalent loading $F_{e}$ is addressed in Harris Ch21. The "basic dynamic capacity of a bearing" $C$ can be determined from online catalogues (e.g., NTN corporation's Ball and Roller Bearings catalogue ${ }^{24}$ ). For the Project 4 Gears project, it is required to provide horsepower (HP) capacity equations (power, torque, rotational speed relationship) and loading conditions (HP, forces, moments, torques, impacts, etc.) including RPM loading conditions.

Task 1.5 Fatigue Tests, Failure Criteria and Fatigue Failure Mechanisms (TEAM): Discuss the various fatigue strength load treatments: Rotating bending, reverse bending, reverse axial 
loading, reverse torsional loading. Describe the fatigue tests that are relevant for this project (e.g., rotating bending, reversed bending, reversed axial loading, reversed torsional loading, reversed Biaxial loading, Weibull, etc.). How are fatigue related tests used to develop S-N Fatigue curves with endurance limits that depend on N \# of cycles? Does the "knee" exist in the S-N Fatigue curve for the material of the selected mechanical component? Describe the relevant fatigue tests, failure criteria and fatigue failure mechanisms for the mechanical component. Discuss various failure theories (e.g., Ch. 6 of textbook ${ }^{6}$ ) including maximum-distortion-energy theory (i.e., von Mises), maximum shear stress theory, and "Mohr and Modified Mohr" theories. Discuss bi-axial failure criteria for biaxial loadings. Discuss failure as it relates to tri-axial loadings. Discuss failure due to ductile vs. brittle materials. Discuss the role that the general form of the von Mises stress equation (i.e., equivalent or effective stress) plays in fatigue failure. For the Project 3 Bearings project, practical testing considerations are reviewed in Ch19 and $\mathrm{Ch} 23$ of Harris ${ }^{16}$. How are test samples used in endurance testing? What are the test rig design considerations? How is element testing done? How is rolling-sliding contact friction testing done? What types of fatigue tests are relevant for bearings? Discuss various underlying physical phenomena of fatigue due to rolling contact stresses; these are reviewed in Harris (e.g., Ch18, Ch22, Ch23, Ch24 and Ch27); examples are given in Table 7.

Table 7 Examples of underlying physical phenomena of fatigue due to rolling contact stresses wear damage, failure mechanisms, mechanical damage, crack damage, microcracking, surface initiated cracks, sub-surface initiated cracks, lubricant deficiency, corrosion damage, Brinell marks (Brinelling), false Brinell marks, score marks, adhesion damage, lubricant contamination, fretting corrosion, spalling (flaking), fine particle dispersion, hydrolysis, particle dents, electric arc damage, microvoid coalescence, cleavage, intergranular fracture, microscopic fatigue, microstructural damage (dark-etching areas and effect of hardness HRC critical factor; white-etching regions), pitting, butterflies in fatigued ball bearings, fish-eye fatigue

Task 1.6 Fatigue Models (TEAM): Describe the relevant fatigue models along with the parameters that are needed in performing fatigue life analysis. What is a Haigh diagram? What quantities are plotted in making up a fatigue plot? When are mean/alternating stresses used and when are $\mathrm{min} / \max$ stresses used? The TEAM must select a reliability factor for use in its fatigue calculations. For Project 1 Fasteners, consider $\mathrm{Ch} 8$ textbook $^{6}$ and discuss various fatigue models such as Goodman line, Gerber parabola, Soderberg line, Modified Goodman, Modified Gerber, Cook, and Gunn ${ }^{8}$. What is meant by stress concentration factor, $\mathrm{K}_{\mathrm{t}}$ ? What are the quantities and their values that affect stress endurance limits (e.g., fatigue stress concentration factor, notch sensitivity factor, unnotched vs. notched, "bending, axial, or torsion" loading, surface, size, loading, temperature, reliability, concentration notch, etc.) Consider Peterson's Stress Concentration Factors ${ }^{10}$. For combine stresses consider Gough's work on "Some Experiments on the Resistance of Metals to Fatigue under Combined Stresses ${ }^{11}$ ". How is the fatigue safety factor computed? For Project 2 Springs, why are torsional stresses utilized in helical compression spring fatigue models? How does surface conditioning like "shot-peened" affect the "stress endurance limit" and fatigue life? For Project 3 Bearings, consider steel composition, 
processing bearing internal load distribution, variable loading, lubrication, material, contamination and the effects that they have on fatigue life (e.g., Harris ${ }^{16}, \mathrm{Ch} 18, \mathrm{Ch} 19, \mathrm{Ch} 20$, $\mathrm{Ch} 21$, and Ch23). What is meant by fatigue life dispersion? What is meant by dynamic capacity and life of a rolling contact? What is meant by load rating standards? What are the limitations of the Lundberg-Palmgren theory? What are the various fatigue life factors that must be used with the "bearing rating" method? What exponent is relevant for use with the "bearing rating" method of fatigue life (i.e., Harris ${ }^{16}, \mathrm{Ch} 18$ and Ch19 and textbook ${ }^{6}$, Ch14)? Use experimental data and determine the two parameters of the "Two-Parameter Weibull Distribution" for the material of the bearing (e.g., Ch18 and Ch20 of Harris ${ }^{16}$; Popgoshev, et al. ${ }^{18}, \mathrm{McCool}^{19,20}$, Stickles $^{21}$, Johnson ${ }^{22}$ and Murthy, et al. ${ }^{23}$ ). Estimate fatigue life making use of the maximum Hertz stress $\sigma_{\text {max-test }}$ from experimental data together with the maximum Hertz stress $\sigma_{\text {max-TEAM }}$ computed using the TEAM's loading condition (i.e., Harris ${ }^{16}$, Ch6). For Project 4 Gears, discuss areas on gear teeth where gears can fail (e.g., tooth bending and Hertzian contact). Discuss various underlying physical phenomena of fatigue due to tooth bending and that due to rolling contact stresses in gear teeth.

Task 1.7 List References (TEAM): Utilized appropriate literature resources and list all references used by team.

Task 3.1 TEAM Summary and Conclusions: (a) Superimpose all individual fatigue plot results onto final TEAM fatigue plot results. That is, take all six (6) individual fatigue results and place them on a single TEAM's fatigue analysis plot, complete with TEAM's fatigue model and individual's fatigue safety factors. (b) Summarize team's major results and overall statement about fatigue results. (c) Comments on what you learned in the project. (d) Lessons Learned: What would TEAM do differently the next time?

Task 3.2 TEAM Contributions: Note that each individual team member writes his/her own Section 2 under own name. Report contributions per Team Member must be indicated for Sections 1 and 3. For example, Susan, Bob, and Jim equally contributed to writing Section X; Tom, David, and Sally equally contributed to writing Section Y. Then summarize all writing contributions per team member according to how many total pages each wrote and contributed to all Sections 1-3. For example: Susan wrote 5 pages; Bob wrote 4 pages; Jim wrote 6 pages; Tom wrote 5 pages; David wrote 5 pages; and Sally wrote 7 pages.

Task 3.3 TEAM Level of Effort: Each team member documents the number of hours spent on project.

\section{Project Report Tasks-INDIVIDUAL (50\%)}

Task 2.0 Report Basics (INDIVIDUAL): Report format is followed. The report is written like a report (not like website topics). This section of the report is integrated and written as written by one person and is an appropriate length. Format for report includes the same requirements as Task 1.0 (TEAM). 
Task 2.1 Design and Statics (INDIVIDUAL): Describe loading condition acting on the mechanical component and show all forces and moments. Provide free body diagram (FBD) and static equilibrium equations. For Project 1 Fasteners, what values are used for the friction coefficients and how much torque is used? For Project 2 Springs, how much axial force is used? For Project 4 Gears, apply the methods of Sample Problems 15.1D, 15.2, 15.3, 15.4, 15.5D in textbook ${ }^{6}$ as they relate to "design and statics". Using loading condition, investigate "design and statics" aspects of "gear horsepower capacity for tooth-bending fatigue failure" (i.e., see Sample Problem 15.3) and "gear horsepower capacity for tooth surface fatigue failure" (i.e., see Sample Problem 15.4).

Task 2.2 Stress Analysis (INDIVIDUAL): Perform "worst case" stress analysis, indicating location of worst case stresses. Provide 3D stress element diagrams for worst case stresses. Use the general form of the von Mises stress equation to compute the equivalent or effective stresses for fatigue failure analysis. For Project 3 Bearings, compute maximum Hertzian contact stress $\sigma_{\max }$ based on loading condition (e.g., see Harris Ch6). Consider additional stresses that may be due to centrifugal loading (speeds), hoop stresses (inner-ring press fits) caused by interference fit between inner ring and shaft and residual compressive stresses. For Project 3 Bearings and Project 4 Gears, determine worst case stress elements based on subsurface location depth and perform subsurface stress analysis and Mohr circle stress analysis as function of depth and determine principal stresses, shear stresses, maximum orthogonal shear stresses, and associated 3D stress elements. For Project 4 Gears, compute tooth bending stresses (Lewis type) and Hertzian contact stresses (mean and alternating). Determine "gear horsepower capacity for tooth-bending fatigue failure" and "gear horsepower capacity for tooth surface fatigue failure".

Task 2.3 Fatigue Failure Analysis and Life Expectancy (INDIVIDUAL): Perform fatigue failure analysis and determine fatigue life expectancy in terms of both the "number of "stress reversal" cycles before failure and the "number of years" of operation before failure. Plot "alternating and mean stresses" or max/min stresses operating point on fatigue analysis plot and determine fatigue safety factor. Determine life expectancy of mechanical component based on loading conditions.

Task 2.4 Simulation (Bonus) (INDIVIDUAL): Individual uses commercial simulation software (e.g., Solid Works, Pro/Engineer/Mechanica, ANSYS, etc.) and successfully performs stress analysis of the mechanical component under his/her loading conditions (i.e., FEA Analysis, structural, thermal, etc.). Describe the CAD software used and for what purpose. Describe the Boundary Conditions and applied loads on mechanical component. Describe the treatment of loads (magnitudes, type, and placement), treatment of constraints (type and placement) and assumptions used in the simulation. In your write up, include the following-quantitative values of stresses; max values of stresses; min values of stresses; locations of worst case stresses; stress values at worst case locations; quality of meshing; and "pretty" pictures (color coded stress contours). Do a reality check on your simulation results (do max stress and displacement numbers make sense for intended application of mechanical component). 
Task 2.5 Calculations Documented in Excel File (INDIVIDUAL): Document your individual calculations on your one "Excel" page in the TEAM's Excel File. The calculations made in the Excel file must match those presented in the report; notes in the Excel files must refer to equations numbers, etc. in the report.

Task 2.6 Summary/Conclusions (INDIVIDUAL): (a) Summarize major results and overall statement about fatigue results. (b) Comments on what you learned in the project. (c) Lessons Learned: What would you do differently the next time?

Task 2.7 List of References (INDIVIDUAL): Reference all appropriate literature resources used in your individual report.

\section{Team Presentations and Rubrics for Grading Presentations}

Teams give presentations during the final week of the project; 4 teams present on Tuesday and 4 on Thursday. Since there are 4 projects (one each for fasteners, springs, bearings and gears), each team makes 4 presentations. All Team presentations are limited to 12 minute presentations plus 5 minutes for questions. The grace period is 1 minute either way. A team that presents under the 1 minute grace period (i.e., less than 11 minutes) has its presentation grade reduced by $10 \%$; a team that goes over the time limit plus grace period has its presentation grade reduced by an $\mathrm{X} \%$. In the three years of teaching this hands-on method, $\mathrm{X}=10 \%-50 \%$ has been used and the results show that $50 \%$ gets such a strong message across that no team exceeds the "overtime" grace period. The Tuesday/Thursday class is scheduled for 1 hour and 15 minutes. Four (4) teams present during the 75 minutes; that is about 19 minutes max allowed per team. With 5 minutes for questions and 1 minute for "team-podium" transitions, the max time allowed reduces to 13 minutes per team. The 5 minutes provided for questions has proven to be a valuable learning experience for students wherein they learn to field questions better from their peers as well as from engineers from industry (i.e., some questions are on target, but some are off-thewall). It is stressed to the class that it is their audience that decides the value of their presentation, not the presenters. It is stressed to the class that the "decision-makers" in the audience, in general, may be composed of people who are judging the quality of their work by how they receive it, not on the team's presumed technical merits. Presenters need to work at selling their work to the audience, seeking for a strong buy from them. Questions from the audience target quality of technical work. In addition, the technical merit of their work is evaluated under a microscope by the instructor in the review of their reports (which counts for $60 \%$ of project grade); all teams submit a technical report of their work on each project to the instructor. Each team member's presentation time is limited to about 2 minutes. Each team member is required to prepare at least 2 slides for the team's presentation. An example of slides for team presentations is given to the class (see example of slides in Table 8). This example serves two purposes. First, it drives home the point that one slide per minute is an acceptable pace for the presentation; recall that the team's presentation is about 12 minutes. Second, the team only has enough time to present the most important results; questions dig deeper into those 
results. Teams are given the freedom to modify the format to whatever works best for them; teams are encouraged to develop their own format so that their project results are presented in the best light.

Table 8 Example of Presentation Slides Slide 1: Title Slide: Course, Date, Team\#, Project, Vehicle, Mechanical Component, Team Members; Provide the names of team members of the six team positions- Project Leader, Project Chief of Staff, Integrators1-4.

Slide 2: Project Definition, Goals, Vehicle, Component Slide 3: Utility, Technology, Manufacturing, Economics, Safety Issues

Slide 4: Dimensions, Materials, and Environmental Conditions:

Slide 5: Loading Conditions (all team members)

Slide 6: Design and Statics (all team members) Slides 7 and 8: Stress Analysis (results of all team members) Slides 9 and 10: Simulations of Mechanical Component (if available)

Slides 11 and 12: Fatigue Failure Analysis (all team members)

Slide 13: Life Expectancy (all team members)

Slide 14: Summary and Conclusions (all team members) References (cite these on the slides that they are used)

Engineers from industry and government labs are invited to take part in judging all team presentations and to provide feedback comments for the teams. Rubrics are provided in Table 9.

Table 9 Rubrics for Presentation Grading (scores: 0-1 in each category)

\begin{tabular}{|c|c|c|c|}
\hline & Assessment Rubrics: Presentation Grading & Max & Team \\
\hline Q1 & $\begin{array}{l}\text { Project description and technical approach clear to audience (information targeted audience?) } \\
1.0 \text { Excellent; } 0.9-0.95 \text { Very Good; } 0.8-.9 \text { Good; } 0.7-0.8 \text { Average; } 0.5-0.7 \text { Below Average; } 0.5-0.1 \text { Vague }\end{array}$ & 1 & \\
\hline Q2 & $\begin{array}{l}\text { Well organized presentation (well-prepared, well-rehearsed, polished?) } \\
1.0 \text { Excellent; } 0.9-0.95 \text { Very Good; } 0.8-.9 \text { Good; } 0.7-0.8 \text { Average; } 0.5-0.7 \text { Below Average; } 0.5-0.1 \text { Poor }\end{array}$ & 1 & \\
\hline Q3 & $\begin{array}{l}\text { Clarity of presentation (purpose, content, visuals, data, analysis, message understood?) } \\
1.0 \text { Excellent; } 0.9-0.95 \text { Very Good; } 0.8-.9 \text { Good; } 0.7-0.8 \text { Average; } 0.5-0.7 \text { Sketchy; } 0.5-0.1 \text { Confusing }\end{array}$ & 1 & \\
\hline Q4 & $\begin{array}{l}\text { Presentation stimulated audience's interest (Attention-Getter, powerful; Q\&A: confidently and easily?) } \\
\text { 1.0 Memorable; } 0.9-0.95 \text { Very Interesting; } 0.8-.9 \text { Good; } 0.7-0.8 \text { Average; } 0.5-0.7 \text { Sketchy; } 0.5-0.1 \text { Little }\end{array}$ & 1 & \\
\hline Q5 & $\begin{array}{l}\text { Team communicated well throughout presentation (knows topic, good eye contact, clear, audible?) } \\
1.0 \text { Outstanding; } 0.9-0.95 \text { Very good; } 0.8-.9 \text { Good; } 0.7-0.8 \text { Average; } 0.5-0.7 \text { Sketchy; } 0.5-0.1 \text { Limited }\end{array}$ & 1 & \\
\hline Q6 & $\begin{array}{l}\text { Team demonstrated critical thinking skills, initiatives, and innovation (analysis, solutions, ideas, etc.?) } \\
1.0 \text { Impressive; } 0.9-0.95 \text { Very Clever; } 0.8-.9 \text { Clever; } 0.7-0.8 \text { Average; } 0.5-0.7 \text { Sketchy; } 0.5-0.1 \text { Lacking }\end{array}$ & 1 & \\
\hline Q7 & $\begin{array}{l}\text { Team exhibited enthusiasm for project } \\
1.0 \text { Substantial; } 0.9-0.95 \text { Very Strong; } 0.8-.9 \text { Strong; } 0.7-0.8 \text { Average; } 0.5-0.7 \text { Sketchy; } 0.5-0.1 \text { Limited }\end{array}$ & 1 & \\
\hline Q8 & $\begin{array}{l}\text { Team demonstrated ability to function as group (teamwork visibly evident?) } \\
1.0 \text { Remarkable; } 0.9-0.95 \text { Very Evident; } 0.8-.9 \text { Evident; } 0.7-0.8 \text { Average; } 0.5-0.7 \text { Sketchy; } 0.5-0.1 \text { Limited }\end{array}$ & 1 & \\
\hline Q9 & $\begin{array}{l}\text { Team finished on time (10-12 minutes) (Timing?) } \\
1.0 \text { Great; } 0.9-0.95 \text { Very good; } 0.8-.9 \text { Good; } 0.7-0.8 \text { Marginal; } 0.5-0.7 \text { Near Margins; } 0.5-0.1 \text { Way Off }\end{array}$ & 1 & \\
\hline Q10 & $\begin{array}{l}\text { Presentation well prepared/professionally presented (Effectiveness, quality, "oral and eye" aspects?) } \\
1.0 \text { Excellent; } 0.9-0.95 \text { Very Good; } 0.8-.9 \text { Good; } 0.7-0.8 \text { Average; } 0.5-0.7 \text { Below Average; } 0.5-0.1 \text { Poor }\end{array}$ & 1 & \\
\hline & $\begin{array}{lc} & \text { Total Points } \\
\end{array}$ & 10 & \\
\hline
\end{tabular}

\section{Lessons Learned-Students}

This is a course that has the structure described above; but it is not a course in which everything is handed to the student. It is a course that requires thinking through real mechanical components and dealing with uncertainty. Students need to step out of their comfort zone and seek any information and data not provided. They need to read the textbook and reference material carefully and decide on what fundamentals are to be used and how to apply them. There is no single right answer, but many potentially wrong answers. Grading is based more on good 
versus bad engineering judgment, valid versus invalid assumptions, appropriate versus inappropriate equations, realistic versus unrealistic loading conditions, adequate versus inadequate free-body diagrams, reasonable versus unreasonable method of approach, reliable versus unreliable data, acceptable versus unacceptable results, and "numbers in the ballpark" versus those that make no sense. The grading in the course is designed to encourage students to think for themselves as well as brainstorm with their peers. The following feedback from students expresses sentiments of the class:

"I learned way more on this project than I could have imagined. Group project in past courses were never much of a teaching tool. It was more of just another simple assignment to complete. This project was quite different. We were given little direction, which was a shocker at first. As the project developed, I notice how much my problem solving skills and critical think skills had improved in such a short time. Most projects we are fed all the information needed. Having only little information and knowledge of the project to go off of I really had to step out of my comfort zone. I learned to put the engineering core courses to good use to better understand the analysis. My prior knowledge from solid mechanics was used to learn the new topic of fatigue. It was great to do stress-strain analysis and fatigue analysis on something realistic instead of just theoretical like usual. I learned to interpret and construct fatigue models and study the life of a mechanical component." "One of the main lessons learned was to begin the project as if the knowledge of the project is minimal. Make no assumption that the knowledge is already in your mind." "This project is essentially the first practical project we've had in our engineering education that has taught us something about what the real world of engineering is like."

Students learned to be more organized from the start of a project, to make decisions faster, and to complete tasks in a timely manner (i.e., time management). Examples of lessons learned about the value of teamwork are given below:

"Our group found that some people are better than others at specific parts of the project and by everyone using their strengths we were able to teach others the necessary skills to understand the full analysis. As a team we definitely plan to take advantage of the knowledge of others." "I learned a great deal about how to work with a group as well. Certain people have their own strengths and weaknesses and if you can play on those strengths the project will work much smoother." "On a personal note, I learned that teamwork does trump individual talent." "For the next project, I have learned to work ahead. I cannot let the work pile up until the very last minute to submit the final report. Procrastination is not an option." "Some of the things that we want to do better moving forward would be to set a meeting schedule in stone at the beginning of each week so that we are able to accommodate for everyone's classes, commitments and personal life. We can also improve on our time management and efficiency of our meetings." "I have learned how important it is to work on a team. For this project our team dynamics were very essential to the entire thought process throughout the entire project; we collaborated very effectively and succeeded by "bouncing ideas off of one another" constantly." "We 
were not as efficient as keeping track of time as we should have been." "It is also teaching me how to interact effectively with a variety of personalities. One of the major faults of this project is the relaxed nature that many members took. Many members assumed they understood the loading scenarios, and then, instead of getting ahead, waited too late to realize that the assumption we made were wrong, and had to redo most of the work leading to very late and stressful nights of working." "As team you learn and grow from the obstacles you face and we have been able to overcome each one of them by working together and helping one another." "For next projects I will be creating a schedule to more effectively manage our time and complete the report in a timely fashion."

Examples of lessons learned about communications are given in the following:

"The way we helped prevent confusion throughout the process of this project was by meeting frequently for updates and question and answer sessions. This was extremely helpful. Last project we meet for long periods of time, but less often. The frequent meetings were more beneficial insuring everyone was at the same stage of the project at the same time. All questions were being answered faster and if changes needed to be made they were fixed immediately." "Next time we need to sit down and discuss our approach as a team early on." "I would also start the project sooner and look at problems that might come up in the future and make preparations for any obstacles that might cause delays in the project." "We experienced a collaborative process and in doing so learned not only about our team members, but about our own personal ability to work within a team. This experience has taught us just how important effective communication is and the consequences of exercising poor communication practices. Most importantly, we are learning to trust each other with task and responsibilities. It has become easy to see that it would be very difficult for one person to do everything, thus the need to a collaborative effort." "From this project I learned how to prioritize as a leader and designate tasks as well as listen to everyone in the group and make decisions."

Examples of lessons learned include the following:

"One lesson learned was how to make assumptions and simplifications for our loading cases while still upholding the integrity of our calculations." "In this project, I learned to make engineering assumptions." "We have learned to be more thorough in our research tasks and the importance of properly documenting sources." "While it is necessary to make some assumptions, care should be taken as a hastily made assumption may lead you down the wrong path and increase the overall workload."

An example of lessons learned about presentations is the following:

"I also feel like my public speaking abilities improve every time we have a presentation. Every time I am up at the front of the classroom I feel more confident and comfortable relating knowledge to my peers. I am excited to continue having presentations, because I feel like my public speaking skills will only continue to improve." 


\section{Lessons Learned-Instructor}

During the course's three offerings, the instructor has made some minor changes and fine tuning to increase learning and understanding. The course has been taught as (a) 100\% team-based/0\% individual-based and (b) 50\% team-based (i.e., Sections 1 and 3 of report) and 50\% individualbased (i.e., Section 2 of report) as described above. Under (a), team members were required to learn from each other in all aspects of the projects. A sufficient number of students short circuited that requirement with the attitude that if one of their team members got a particular aspect of a task completed, it was good enough without the rest of the team understanding or learning how to do that aspect. Under (b), each team member was required to develop own loadings to use in individual stress and fatigue analyses (i.e., Section 2 of report). Learning increased and understanding improved substantially with (b). The course has been taught using (a) peer grading of project presentations and (b) engineers from industry evaluating presentations, replacing peer evaluations. Under (a), it was observed that some students completed their peer evaluations with $100 \%$ scores even before presentations took place. Students put more effort into the projects with (b). Initially, the first offering was set up with five projects-each three weeks in duration. It was learned that projects 3 (bearings) and 4 (gears) required four weeks each to complete; the fifth project was cancelled. Progress draft reports are due at the end of each class period. Two methods were tried in grading the progress reports: (a) team self-assessment grading of progress reports and (b) instructor grading the progress reports. Under (a), most teams self-assessed at $100 \%$ levels. Under (b), productivity on progress reports skyrocketed. Productivity and learning by all students increased in all aspects of the course where the instructor assessed and graded.

\section{Teaching for Understanding and Experiential Learning}

The hands-on method of teaching the Design of Mechanical Components course is embedded with Perkins' six priorities ${ }^{3}$ for “teaching for understanding".

Perkins 1. The hands-on method has a strong focus on getting students to think for themselves, figuring out their own methods of solution.

Perkins 2. Each class period is focused on project criteria, feedback from instructor, and reflection throughout the learning process of the four projects; engineers from industry provided additional feedback to students regarding their presentations.

Perkins 3. The four projects based on real vehicles and real components provide imagistic, intuitive, and evocative representations to support students' understanding performances.

Perkins 4 . The four projects based on real vehicles and its components provide an ample amount of complexity and uncertainty, encouraging students to utilize more thinking in performing loading, stress and fatigue analyses.

Perkins 5. The four projects based on real vehicles and its components explicitly raised consciousness/awareness about the structure and logic of the fatigue, failure, and life expectancy of mechanical components that transcends into all components, not just those studied. 
Perkins 6. The four projects based on real vehicles and real components provide a model that can be used extensively for reaching far into many different types of studies of real systems.

The hands-on method of teaching the Design of Mechanical Components course provided many instances of concrete experience, reflective observation, abstract conceptualization, and active experimentation. In carrying out active experimentation ${ }^{4}$, teams make decisions about what assumptions are relevant and use theories of science and engineering in processing six different loading conditions from min to max load conditions that approach or surpass fatigue and failure of mechanical component under realistic conditions of operation. They experience how a "spectrum of loading conditions" affects the fatigue and failure life of mechanical components. Furthermore, teams take measurements on their mechanical components, perform real experiments with data acquisition while vehicle and mechanical component are in operation, and compare results and findings with experimental data documented in the literature.

Wurdinger and Carlson ${ }^{5}$ six principles are embedded in the hands-on method. Each project is a problem solving process treating real-life problems with direct experience. It allows students to reach out to worldwide resources in order to perform on project. It encourages peer interaction and teamwork. It uses multiple mechanical components and vehicles to enhance interdisciplinary learning.

\section{Feedback from Students and Engineers}

Feedback has been positive from students that have taken the class and from engineers in industry who served as judges of the students' presentations. Quotes taken from their letters are presented below.

Comments from three students after they had taken the class:

Student\#1: "Enter Design of Mechanical Components taught by Professor Harold Stalford: a class characterized by very little lectures, but lots of self-taught material and self-learning. Now this was an unorthodox form of teaching. It forced us to go out and "turn the world upside down" for information. It truly was, up until that point, the first real engineering class I had taken at the university. The Design of Mechanical Components class is the best course I have taken at this university. "

Student\#2: "I hope that the Design of Mechanical Components class will continue to be taught this way and that other design classes will adopt this style of curriculum. I benefitted from Dr. Stalford's course because it forced me to learn how to use all the resources available to me to solve a problem. I believe that proof that this curriculum is successful could be seen as the semester progressed. At the conclusion of the class, the groups were capable of working with a team under tight time constraints to produce quality material. I saw individuals greatly improve their public speaking abilities during the semester.”

Student\#3: "I learned some of the most important skills required of an Engineer from the class, but some of the most rewarding aspects I learned are the importance of communication, organization, presentation skills, research, and the significance of computing various analyses. When I look back on everything I 
learned from this class, I am very thankful to have had the opportunity to experience a class structured the way it was. All of the engineers at GE were impressed enough during my interview to offer me a great job and I am beyond thankful for the struggle that came with learning all the valuable lessons I learned in Dr. Stalford's Design of Mechanical Components class."

Comments from three engineers in industry that participated as judge in the class:

Engineer \#1: "Dr. Stalford's method has greatly enhanced the "real-world" experience he is trying to provide his students...I hope that Dr. Stalford's method will not only continue to be the gold standard for Design of Mechanical Components, but also utilized in additional courses within the school and the college."

Engineer \#2: "I wish that I had had this class when I was a student...I believe this kind of experience better prepares our graduates for the real world and will help them to distinguish themselves from engineers from other universities."

Engineer \#3: “Dr. Stalford's Design of Mechanical Components students learn to work as a team to research and present their findings in a short timeframe. That is real world. I have told Dr. Stalford and his students that I wish I had been able to take a course like his when I was in school. The team building and presentation skills that Dr. Stalford's students acquire in his Design of Mechanical Components class are invaluable."

\section{Summary}

The hands-on method, presented herein, was developed for use in a junior level course in the School of Aerospace and Mechanical Engineering called "Design of Mechanical Components", fine tuned over the three spring semesters 2012, 2013 and 2014. It is a course in which students learn the fundamentals about fatigue, failure, and life expectancy of mechanical components. Students form teams and pick their own vehicle and components to be investigated in four class projects. Basically, students develop their own problems to solve, all within the guidelines of the course as described above. Students are recommended to read various references, find their own resources, think on their own in solving their own projects with no known answers. The class environment of the hands-on teaching method is conducive for students to "do things to learn" verses "sitting and listening to someone lecture to learn". Details are given above on all aspects of its pedagogy, structure, requirements on all team-based project tasks, rubrics for grading all aspects of a team reports and team presentations and overall course grading method. The handson method instills students' understanding of the key course concepts. It is embedded with Perkins' six priorities ${ }^{3}$, Kolb's four basic elements of the learning cycles ${ }^{4}$, and the six guiding principles of Wurdinger and Carlson ${ }^{5}$ for experiential learning.

Engineers from industry, serving as judges, evaluated the students' presentations and the course. Students and the engineers have given strong positive feedback about the course's educational value, as noted in the samples presented above. Some suggested the method as a gold standard for such courses. Students refer to it as the first real engineering class taken in the curriculum. 
Lessons learned by students include the improved skills in problem solving, critical thinking, public speaking and teamwork. The grading in the course captures "how a student thinks" is as well as "how well they brainstorm and teamwork" with their peers. It is not the answers that are graded. Rather grading is focused on students' thinking associated with engineering judgment, valid assumptions, appropriate equations, realistic loading conditions, adequate free-body diagrams, reasonable method of approach, reliable data, acceptable results, "numbers in the ballpark" that make sense, etc. Productivity and learning by all students increased substantially in all aspects of the course where the instructor assessed and graded their work according to "how they think", a key component of Perkins' "apple of understanding”, Kolb's "experiential learning”, and Wurdinger and Carlson's "teaching for experiential learning”.

The hands-on method is portable and can be adapted easily to any field of learning at any level of learning. The following advice may be helpful to those interested in using this method in teaching one of their courses. In the beginning of a course, some students may want to be told how to make every step. They may tend to treat it like a homework problem with "right" answers. Is this the right equation to use? Is this the right data? Is this the right answer? Am I doing everything correctly? Do I have this part right? They may tend to seek the instructor's signoff and validation on everything before their reports are turned in for grading. An instructor may be tempted to give the students solutions instead of allowing the students to work through the solution process, using their own thinking. It may be hard for an instructor to watch students struggling through the process of developing their own methods of solutions when the instructor can easily give them a "helicopter lift" to an end result. In using this method, an instructor can help the students more by responding with questions that encourage students to think for themselves, the key of the method. The hands-on method is designed so that the instructor can mentor and coach students" "thinking and doing" in a multidimensional process of learning. The hands-on method is designed so that peer-to-peer learning is greatly enhanced. The hands-on method is designed so that there is a meeting of the minds between the instructor and the students; students are encouraged to defend their way of thinking. The hands-on method is designed to promote and encourage self-regulated learning.

\section{Bibliography}

1. Feynman, Richard P., 1985, "Surely You're Joking, Mr. Feynman!” Adventures of a Curious Character, W. W. Norton \& Company, New York.

2. Gearon, Christopher J., 2012, High School Students Need to Think, Not Memorize, US News \& World Report, September 17, 2012, http://www.usnews.com/education/high-schools/articles/2012/09/17/high-school-studentsneed-to-think-not-memorize

3. Perkins, David, 1993, Teaching for Understanding, American Educator: The Professional Journal of the American Federation of Teachers; v17 n3, pp. 8, 28-35, Fall 1993.

4. Kolb, D.A. 1984. Experiential learning: experience as the source of learning and development, Englewood Cliffs, New Jersey: Prentice-Hall.

5. Wurdinger, Scott D. and Carlson, Julie A., 2010. Teaching for Experiential Learning: Five Approaches That Work, Rowman \& Littlefield Education, Lanham, Maryland.

6. Juvinall, Robert C. and Marshek, Kurt M., 2012, Fundamentals of Machine Component Design, $5^{\text {th }}$ edition, John Wiley \& Sons, Inc., Hoboken, NJ. 
7. Gere, James M. and Goodno, Barry J., 2013, Mechanics of Materials, Eighth Edition, Cengage Learning, Stamford, CT.

8. Burguete, R. L., Patterson, E. A., 1995, "The effect of mean stress on the fatigue limit of high tensile bolts", Proc. Inst. Mech. Engrs., vol. 209, 257-62.

9. Patterson, E. A., 1990, "A Comparative Study of Methods for Estimating Bolt Fatigue Limits," International Journal of Fatigue Fracture Engineering and Material Structures, 13(1), pp. 59-81.

10. Pilkey, Walter D. and Pilkey, Deborah F., 2001, Peterson's Stress Concentration Factors, $3^{\text {rd }}$ Ed., John Wiley \& Sons, Inc., 2008.

11. Gough, H. J., Pollard, H. V., Clenshaw, W. J., 1951, Some Experiments on the Resistance of Metals to Fatigue under Combined Stresses, London, Parts I and II, Monograph 2522, Aeronautical Research Council Reports and Memoranda, Ministry of Supply, His Majesty's Stationery Office, London.

12. Wahl, A. M., 1963, Mechanical Springs, $2^{\text {nd }}$ Ed., McGraw-Hill, New York.

13. Spotts, M. F., 1978, Design of Machine Elements, $5^{\text {th }}$ Ed., Prentice-Hall, Inc., Englewood Cliffs, New Jersey.

14. Spring Design Manual, 1996, AE-21, $2^{\text {nd }}$ Ed., Society of Automotive Engineers, Inc., Warrendale, PA.

15. Fundamentals of Spring Design, 2000, Spring Manufacturers Institute Inc., Oak Brook, IL.

16. Harris, Tedric A., 2001, Roller Bearing Analysis, $4^{\text {th }}$ Ed., John Wiley \& Sons Inc., New York.

17. Palmgren, Arvid, 1959, Ball and Roller Bearing Engineering, $3^{\text {rd }}$ Ed., S. H. Burbank \& Co., Inc., Philadelphia.

18. Popgoshev, D. and Valori, R., 1982, "Rolling contact fatigue evaluation of advanced bearing steels," Rolling Contact Fatigue Testing of Bearing Steels, ASTM STP 771, J. J. C. Hoo, Ed., American Society for Testing and Materials, pp.342 -357.

19. McCool, J. I., 1982, "Analysis of sets of Two-parameter Weibull data arising in rolling contact endurance testing", Rolling Contact Fatigue Testing of Bearing Steels, ASTM STP 771, J. J. C. Hoo, Ed., American Society for Testing and Materials, pp.293 -319.

20. McCool, J. I., 1979, "Analysis of single classification experiments based on censored samples from the 2parameter Weibull distribution", J. Statistical Planning and Inference, vol. 3, pp.39 -68.

21. Stickles, C. A., 1984, "Rolling contact fatigue tests of 52100 bearing steel using a modified NASA ball test rig," Wear, 98 (1984) 199-210.

22. Johnson, Leonard G., 1964, The Statistical Treatment of Fatigue Experiments, Elsevier, New York, 1964.

23. Murthy, D.N. Prabhakar, Bulmerc, Michael, and Ecclestonc, John A., 2004, "Weibull model selection for reliability modelling," Reliability Engineering and System Safety, 86, 257-267.

24. NTN Catalogue Website: http://www.ntn.co.jp/english/products/pdf/ball/pdf/Bearing_en_all.pdf

25. Dolan, Thomas J. and Broghamer, Edward L., 1942, A photoelastic study of stresses in gear tooth fillets, Engineering Experiment Station Bulletin Series No. 335, University of Illinois, No. 31, March 24.

26. Standard Handbook of Chains, chains for power transmission and material handling, 2006, 2nd Ed., Taylor \& Francis ICRC Press, Boca Raton, Fla.

27. Marshek, K. M., 1979, On the analyses of sprocket load distribution, Mechanism and Machine Theory, 14, 135140.

28. Naji, M. R., and Marshek, K. M., 1983, Analysis of sprocket load distribution. Mechanism and Machine Theory, 18, 349-356.

29. Naji, M. R., and Marshek, K. M., 1983, Experimental determination of the roller chain load distribution, ASME Transactions, Journal of Mechanisms, Transmissions, and Automation in Design, 105, 331-338.

30. Naji, M. R., and Marshek, K. M., 1984, Analysis of roller chain sprocket pressure angles, Mechanism and Machine Theory, 19, 197-203.

31. Eldiwany, B. H. and Marshek, K. M., 1984, Experimental load distribution for double pitch steel roller chain on steel sprockets, Mechanism and Machine Theory, 19, 449-457. 